\title{
ELECTRICAL STIMULATION OF SMOOTH MUSCLE STRIPS FROM THE URINARY BLADDER OF THE PIG
}

\author{
R. van Mastrigt and J.J. Glerum
}

\author{
ABSTRACT \\ Strips of smooth muscle from pig urinary bladders were electrically \\ stimulated to contract. Stimulation parameters and conditions were \\ optimized so as to obtain a maximum number of isometric contractions \\ with maximal force. It was found that the contractions could be described \\ mathematically by a simple model In the model there is a constant \\ probability for cells to pass from the non-contractile to the contractile state \\ during stimulation; this leads to a linearly decreasing phase plot (a plot of \\ the rate of rise of a variable as a function of the variable) for the force.
}

\begin{abstract}
'Activation' of the cells is described by a physical step function. Isometric contractions were thus characterized by a set of three parameters: $U$, the time derivative of the force, extrapolated to zero force, $F_{i s o}$ the value of the isometric force which is approached asymptotically after infinitely long periods of stimulation and $t_{2}$ the activation time. The sensitivity of these three parameters to variation of the stimulus parameters was investigated. It was found that the parameter $U$ was consistently correlated with the stimulus parameters, suggesting that this parameter can be used to describe the effectiveness of electrical stimulation of such strips.
\end{abstract}

\section{INTRODUCTION}

Considerable interest exists in the contractile properties of the urinary bladder ${ }^{1-12}$. In existing methods of clinically determining bladder contractility ${ }^{2,5,8,10}$ the Hill ${ }^{13}$ model for contracting muscle is used, with the assumption that the model holds during the entire contraction. Thus the muscle is assumed to be fully active right from the start of stimulation and to remain so during the entire contraction. From clinical measurements it is clear that this is not a valid assumption, and that the degree of stimulation or activation of the muscle not only builds up in a distinct time interval but may also vary significantly during a contraction ${ }^{10}$.

Moreover, in measurements in vitro of isometric contractions in electrically stimulated strips from pig bladders ${ }^{3,4,9}$ it was found that these preparations not only deteriorated very rapidly, but that the measured isometric forces were low compared with the values published for other smooth muscles ${ }^{14}$.

Finally, there is clinical interest in the electrical stimulation of the detrusor muscle in patients ${ }^{15-18}$. For these reasons the present study of electrical stimulation in vitro of pig bladder strips was undertaken. Its purpose was to optimize the stimulation parameters and conditions, to model isometric contractions, and to derive parameters which describe the effectiveness of the stimulation.

\section{METHODS}

Experiments were performed on urinary bladders from male and female pigs which had been sacrificed after being used for cardiac research. The bladders were removed at the time of death or shortly after, and immediately immersed in cooled

Department of Urology, Erasmus University Rotterdam, P.O. Box 1738, 8000 DR Rotterdam, The Netherlands

(C) 1985 Butterworth \& Co (Publishers) Ltd

0141-5425/85/010002-07 \$03.00

2 J. Biomed Eng. Vol. 7, January metabolic fluid (see below). In the cardiac experiments, various drugs, including Ca-antagonists and beta-blockers, had been administered, sometimes in very large doses, so that an influence on the smooth musculature of the bladder could not be excluded. From each bladder a strip of about $15 \times 30 \mathrm{~mm}$ was excised, with the same orientation, and the tissue volume was determined by weighing it in air and in water. The strip was mounted between clamps with penetrating pins ${ }^{19}$, the lower clamp being fixed near the bottom of a container, and the upper one connected to a Grass FT03C force transducer (set to a full range of $10 \mathrm{~N}$ ), which could be moved vertically in order to change the length of the strip. The initial length was set to yield a passive force of approximately $0.1 \mathrm{~N}$ and during stimulation, the length of the strip was kept constant. The signal from the force transducer was amplified with a standard strain gauge amplifier and recorded on a strip chart recorder. Strips were stimulated to contract electrically by field stimulation, using two platinum electrodes of $20 \times 30 \mathrm{~mm}$, placed about $20 \mathrm{~mm}$ apart with one on each side of the strip. The overall resistance was of the order of $100 \Omega$. The stimulation signal was obtained from a Kepco operational power supply/amplifier, a standard pulse generator and a specially made pulse converter. The voltage, frequency and duration of the pulses and the total duration of stimulation, could be varied.

In order to avoid electrolysis of the metabolic fluid, bidirectional pulse stimulation was used. The special converter inverted every second pulse, so that positive and negative pulses alternated. The voltage level between the pulses was zero.

Two series of measurements were performed:

In the first series, a modified Krebs solution of the following composition was used ${ }^{20}: \mathrm{Na}^{+} 137$;

$\mathrm{Ca}^{2+} 2.5 ; \mathrm{K}^{+} 5.9 ; \mathrm{Mg}^{2+} 1.2 ; \mathrm{Cl}^{-} 134 ; \mathrm{H}_{2} \mathrm{PO}_{4}^{-} 1.2 ;$ $\mathrm{HCO}_{3}^{-}$15.5; glucose $11.5 \mathrm{mMol} / \mathrm{l}$. The fluid was 
kept at $37^{\circ} \mathrm{C}$ and aerated with $95 \% \mathrm{O}_{2}$ and $5 \% \mathrm{CO}_{2}$. Its $\mathrm{pH}$ was often rather low (7.0-7.2). In these experiments the maximum active force obtained during stimulation i.e. the increase in force above the passive baseline, was measured on the paper chart and processed manually.

In the second series another modified Krebs solution $^{21}$, closer to the original $\mathrm{Krebs}^{30}$ solution was used, with the following composition in $\mathrm{mMol} / \mathrm{l}: \mathrm{Na}^{+} 143 ; \mathrm{Ca}^{2+} 1.9 ; \mathrm{K}^{+} 5.9 ; \mathrm{Mg}^{2+} 1.18$; $\mathrm{Cl}^{-} 126.5 ; \mathrm{SO}_{4}{ }^{2-} 1.18 ; \mathrm{H}_{2} \mathrm{PO}_{4}^{-} 1.2 ; \mathrm{HCO}_{3}{ }^{-} 25.01 ;$ glucose 11 . The $\mathrm{pH}$ of this fluid, when saturated with the same gas mixture, varied between 7.40 and 7.45. In this second series, the force signal was sampled by a Texas Instruments 980 B digital computer at a samplc rate of $10 \mathrm{~Hz}$. Force recordings of $25 \mathrm{~s}$ duration were stored on disc, together with the times at which the stimulation was switched on and off and the values of the stimulation parameters.

Measurements were performed on a total of 37 strips, 18 in the first series and 19 in the second. On average, 55 contractions were measured on a strip. Except where explicitly stated, strips were stimulated at five minute intervals. In each series of measurements on one strip, one (or sometimes more) stimulation parameter was systematically varied to investigate its influence on the contraction parameters. Except where explicitly stated, an alternating measurement order was used, i.e. a high parameter value, followed by a low value, then the next highest, and so on. To correct for spontaneous changes in contraction parameters due to the elapse of time, a correction contraction with a standard set of stimulation parameters preceded every measurement, so that correction and measurement contractions alternated. In each measurement, in the first series, the measured maximum active force was corrected by multiplying by a factor $F_{1} / F_{n-1}$, where $F_{\mathrm{n}-1}$ was the value of the maximum active force in the preceding correction measurement and $F_{1}$ was its value in the first correction measurement. When the dependence on the length of the strip was investigated, the length was not alternated but was continually increased. In order to avoid very large length changes, the role of the first correction measurement was taken over by a subsequent, corrected measurement, made at a greater length, after every five or ten measurements. Using the corrected data, Spearman's rank correlation coefficients were calculated in order to reveal any dependence of the contraction parameters on time or the stimulation parameters. In case of the length dependence of the contraction parameters, correlation coefficients were calculated for the rising phase of the bi-phasic curves only.

\section{DATA ANALYSIS METHODS}

The contraction recordings stored on disc were processed in the following way: For each measurement, the passive force was determined as the average force level just before stimulation, and subtracted from the measured force to yield active force. The derivative of this force, filtered by adding to each data point the three preceding and the three subsequent samples and dividing by seven, was plotted as a function of active force, to yield a phase plot. To a part of each plot (see Results) a straight line was fitted using a least squares fitting technique:

$$
\mathrm{d} F / \mathrm{d} t=c_{1}\left(F-F_{\text {iso }}\right)
$$

where $F=$ measured force

$$
\begin{aligned}
t & =\text { time } \\
c_{1} & =\text { gradient } \\
F_{\text {iso }} & =\text { intercept of line on force axis }
\end{aligned}
$$

$F_{\text {iso }}$ is the isometric force which is approached asymptotically after infinitely long stimulation, as opposed to $F_{\max }$ the maximal active force actually attained during an isometric contraction.

The intercept $U$ of the fitted line on the $\mathrm{d} F / \mathrm{d} t$ axis is given by:

$U=-c_{1} \cdot F_{\text {iso }}$

Having determined $c_{1}$ by fitting equation 1 to the phase plot, deviations from equation 1 at the beginning of the stimulation period were ascribed to variations in $F_{\text {iso, }}$, which was therefore replaced by the activation $A(t)$, defined as follows:

$A(t)=F-1 / c_{1} \cdot \mathrm{d} F / \mathrm{d} t$

(For this operation the unfiltered $\mathrm{d} F / \mathrm{d} t$ data were used.)

It was found that $A(t)$ could be described mathematically by a physical step function (see Results) consisting of a steep ramp, up to a plateau, as follows:

$\begin{array}{ll}A(t)=t / t_{1} \cdot F_{\text {iso }} & \text { for } t<t_{1} \\ A(t)=F_{\text {iso }} & \text { for } t>t_{1}\end{array}$

Each isometric contraction was thus described mathematically in terms of three parameters, $F_{\text {iso }}, U$ and $t_{1}$.

The correction method applied in the first series of measurements to $F_{\max }$ was applied to all three parameters in this series.

\section{RESULTS}

\section{Optimization of stimulus conditions, first series of measurements}

In three strips, the correction procedure was tested by alternately applying stimulation voltages of $10 \mathrm{~V}$ and $20 \mathrm{~V}$, with the other stimulation parameters held constant (frequency $=20 \mathrm{~Hz}$; pulse duration $=7 \mathrm{~ms}$; stimulus duration $=2.5 \mathrm{~s}$ ). The reproducibility of the quotient of the maximum 


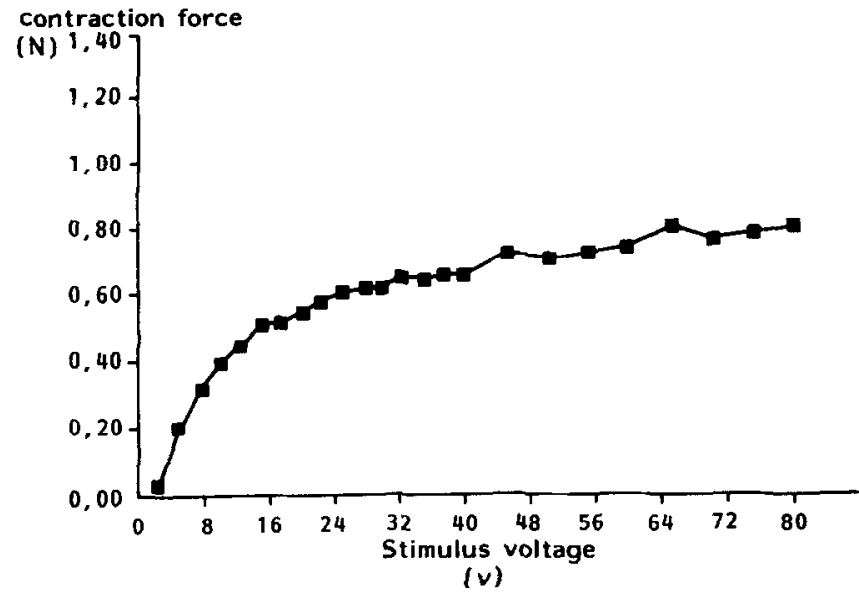

Figure 1 Maximum active contraction force, corrected for spontaneous decay using correction measurements at $20 \mathrm{~V}$ stimulus voltage, as a function of stimulus voltage. Repetition frequency $20 \mathrm{~Hz}$, pulse duration $7 \mathrm{~ms}$, duration of stimulation $2.5 \mathrm{~s}$.

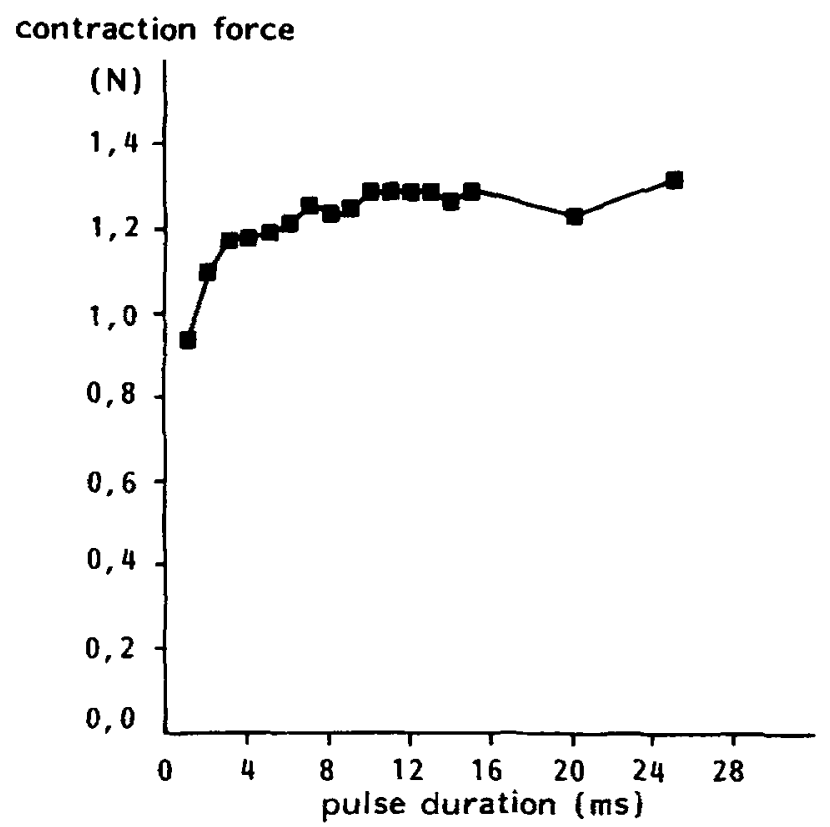

Figure 2 Maximum active contraction force, corrected for spontaneous decay using correction measurements at $5 \mathrm{~ms}$ pulse duration, as a function of stimulus pulse duration. Stimulation voltage $20 \mathrm{~V}$, repetition frequency $20 \mathrm{~Hz}$, duration of stimulation $2.5 \mathrm{~s}$.

active forces at $20 \mathrm{~V}$ and $10 \mathrm{~V}$ was good: the coefficients of variation (standard deviation divided by average) of the quotients were $0.01,0.04$ and 0.05 .

Five strips were used to establish the dependence of the force on the stimulation voltage. Figure 1 shows a typical plot of corrected active force as a function of stimulation voltage, all other parameters remaining unchanged. In all five strips the force rose steeply at first and then less steeply, with increasing voltage. Since in every case the change of slope occurred at or below about $20 \mathrm{~V}$, and since the impression was gained that the higher the stimulation voltage, the more rapidly the strip was exhausted, $20 \mathrm{~V}$ was chosen as the best compromise.
In ten strips the dependence of the contractions on the frequency and duration of the pulses was investigated. It was found that at constant frequency the contraction force increased with increasing pulse duration, up to the point where the duty cycle was $50 \%$, although again the curve flattened off after a steep initial rise, see Figure 2. At higher duty cycles, the curve is difficult to interpret because the bi-directional stimulation signal becomes gradually more similar to a mono- directional stimulation signal of twice the voltage. As shown in Figure 3, at constant pulse duration (7 ms) the contraction force increases dramatically with pulse frequency up to the point where the pulse duration can no longer be kept constant. From data such as that shown in Figure 2 and 3 it was concluded that, with pulse duration set to the maximal duty cycle of $50 \%$, the frequency dependence would also show a maximum at about $100 \mathrm{~Hz}$. We therefore chose $20 \mathrm{~V}, 100 \mathrm{~Hz}, 5 \mathrm{~ms}$ as the best compromise.

In thrce strips, stimulated at $15 \mathrm{~min}$ intervals, the glucose content of the metabolic fluid was determined every hour; no significant decrease in glucose level was found.

\section{Mathematical modelling, second series of measurements}

The different metabolic fluid with increased $\mathrm{pH}$ used in this series of measurements, caused a dramatic increase in the maximum contraction force. The average $F_{\max }$ measured in the last five strips of the previous series was $0.42 \mathrm{~N}$ (standard deviation $0.31 \mathrm{~N}, n=177$ ) as compared to $2.18 \mathrm{~N}$ (standard deviation $0.57 \mathrm{~N}, n=182$ ) for the first five strips of this series. Figure 4 shows three superimposed phase plots from three contractions

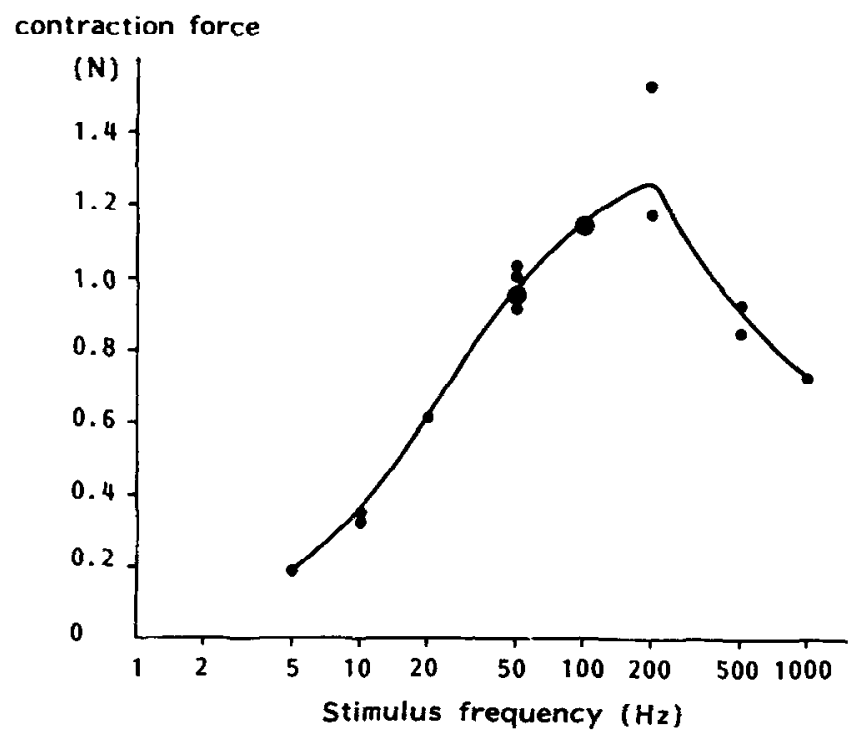

Figure 3 Maximum active contraction force, corrected for spontaneous decay using correction measurements at $20 \mathrm{~Hz}$ repetition frequency, as a function of pulse repetition frequency. Stimulation voltage $20 \mathrm{~V}$, duration of stimulation $2.5 \mathrm{~s}$. Pulse duration was $7 \mathrm{~ms}$ for frequencies lower than $100 \mathrm{~Hz}$, and $5,2.5,1$ and $0.5 \mathrm{~ms}$ at $100,200,500$ and $1000 \mathrm{~Hz}$, respectively. 


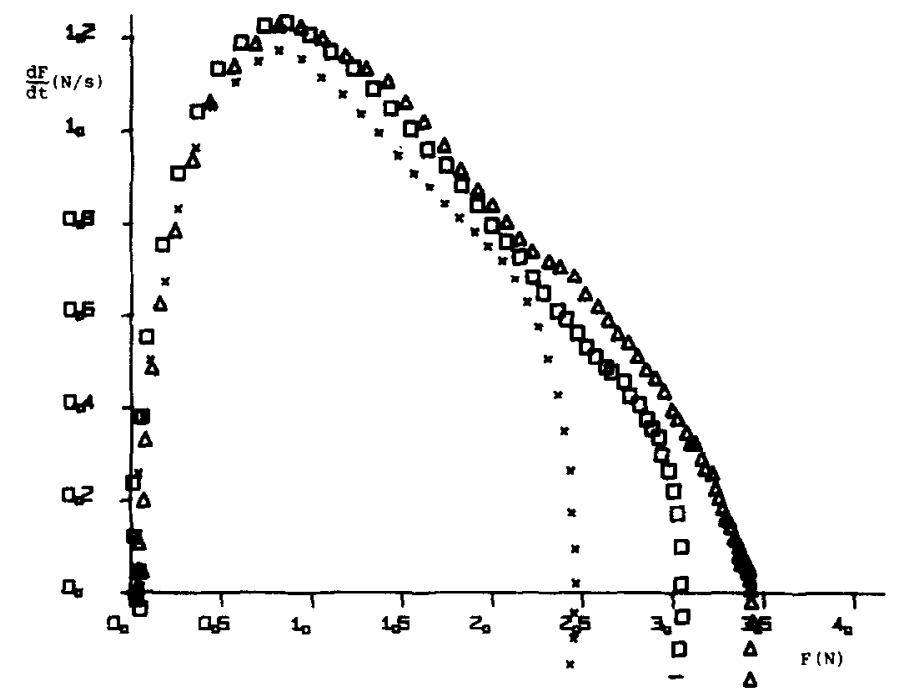

Figure 4 Three superimposed phase plots from three isometric contractions of one strip, stimulated with stimulation voltage $20 \mathrm{~V}$, repetition rate $100 \mathrm{~Hz}$, pulse duration $5 \mathrm{~ms}$ duration of stimulation is $2.5 \mathrm{~s}(\mathrm{x}), 4 \mathrm{~s}(\mathrm{a})$ or $6.5 \mathrm{~s}(\Delta)$.

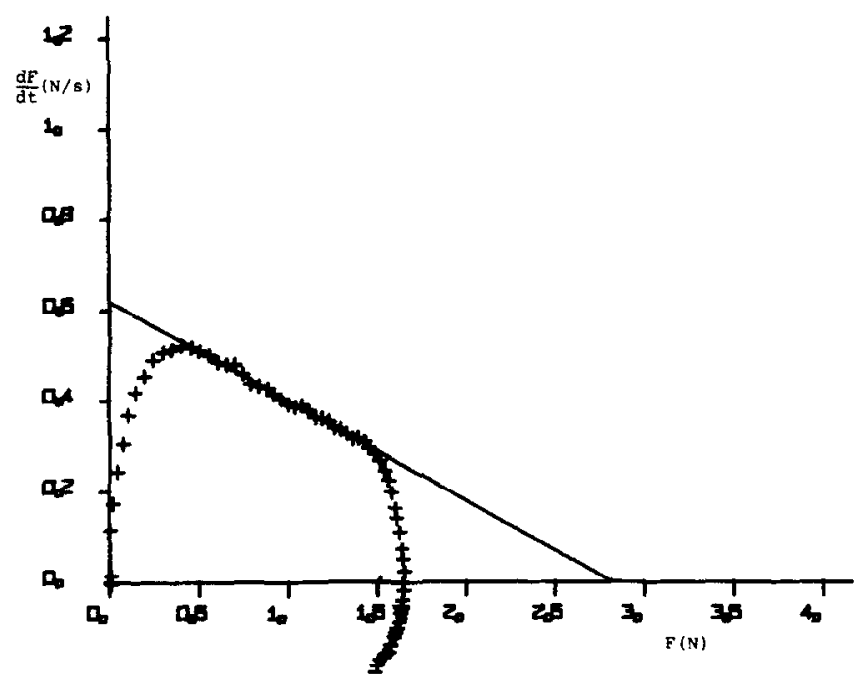

Figure 5 Phase plot from strip stimulated for $4 \mathrm{~s}$ with $10 \mathrm{~V}$, repetition rate $100 \mathrm{~Hz}$, pulse duration $5 \mathrm{~ms}$, with fitted straight line. The parameters estimated from this measurement are $F_{\max }=1.65 \mathrm{~N}, F_{\text {iso }}=2.79 \mathrm{~N}, U=0.62 \mathrm{~N} / \mathrm{s}$.

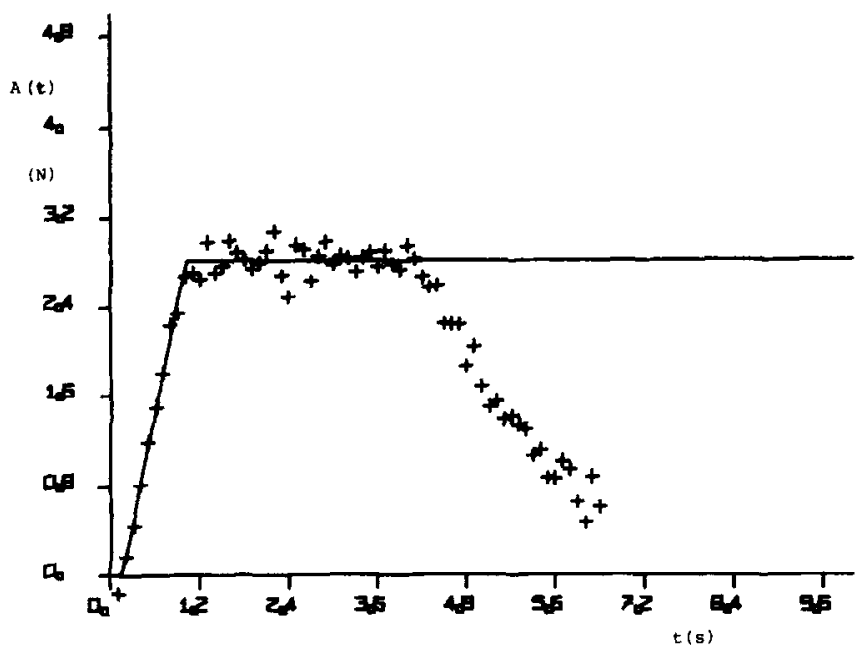

Figure 6 Activation as a function of time, calculated from the data in Fig. 5 with fitted physical step function. The parameter $t_{1}$ is estimated as $0.88 \mathrm{~s}$. measured on one strip. In each case the stimulus parameters were $20 \mathrm{~V}, 100 \mathrm{~Hz}, 5 \mathrm{~ms}$, but the stimulation durations were $2.5,4.0$ and $6.5 \mathrm{~s}$ respectively. It can be seen that all three contractions follow the same rising course, and then begin to follow the same linearly decreasing course ${ }^{22,23}$. Deviation from the straight line begins to occur when the stimulation is turned off. Such a straight line was always observed unless the stimulus duration was very short (less than $1.5 \mathrm{~s}$ ) or the strip was in bad condition. Figure 5 shows a similar phase plot from another strip, together with the fitted straight line (see above). The intersection of the straight line with the force axis represents the force $F_{\text {iso }}$ which the strip would have generated if stimulated indefinitely. The intersection with the $\mathrm{d} F / \mathrm{d} t$ axis is called $U$. Figure 6 shows a plot of the function $A(t)$ versus time. The initial, rising part of the phase plot (Figure 5) corresponds to the ramp in Figure 6. The plateau in Figure 6 corresponds to the straight line in Figure 5, and the deviation from the plateau occurs when the stimulation is turned off. Figure 7 shows the same data on a larger timc scale, so that the linearity of the increase in $A(t)$ can better be judged. The fitted function was described by the parameter $t_{1}$, the rise time of the ramp.

For 12 of the 19 strips in the second series, the correction measurements alone were used to obtain an impression of the time-dependence of the parameters. Table 1 shows the ranges in which the

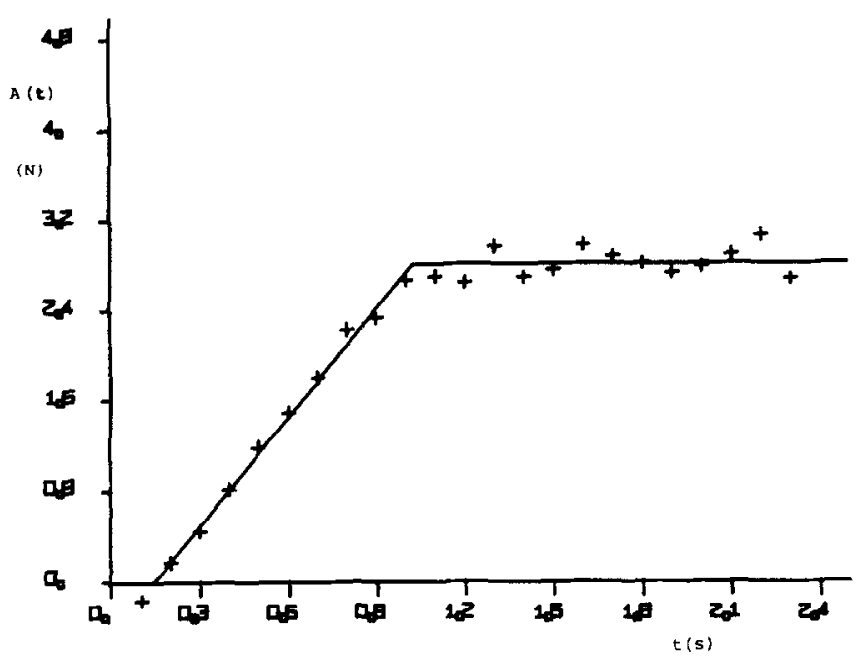

Figure 7 Same data as Fig. 6, but replotted on a larger time scale.

Table I Minimum and maximum average values of parameters per strip

\begin{tabular}{lllll} 
& $\begin{array}{l}\text { Minimum } \\
\text { average } \\
\text { value } \\
\text { of } \\
\text { parameter }\end{array}$ & $\begin{array}{l}\text { Coefficient } \\
\text { of } \\
\text { variation }\end{array}$ & $\begin{array}{l}\text { Maximum } \\
\text { average } \\
\text { value } \\
\text { of } \\
\text { parameter }\end{array}$ & $\begin{array}{l}\text { Coefficient } \\
\text { of } \\
\text { variation }\end{array}$ \\
\hline$F_{\text {nax }}(\mathrm{N})$ & 1.2 & $27 \%$ & 4.2 & $10 \%$ \\
$F_{\text {iso }}(\mathrm{N})$ & 1.5 & $19 \%$ & 5.9 & $13 \%$ \\
$U(\mathrm{~N} / \mathrm{s})$ & 0.65 & $35 \%$ & 1.8 & $15 \%$ \\
$t_{1}(\mathrm{~s})$ & 0.69 & $39 \%$ & 1.4 & $19 \%$ \\
\hline
\end{tabular}

Results from correction measurements only.

Coefficient of variation $=$ standard deviation/average $\times 100 \%$. 


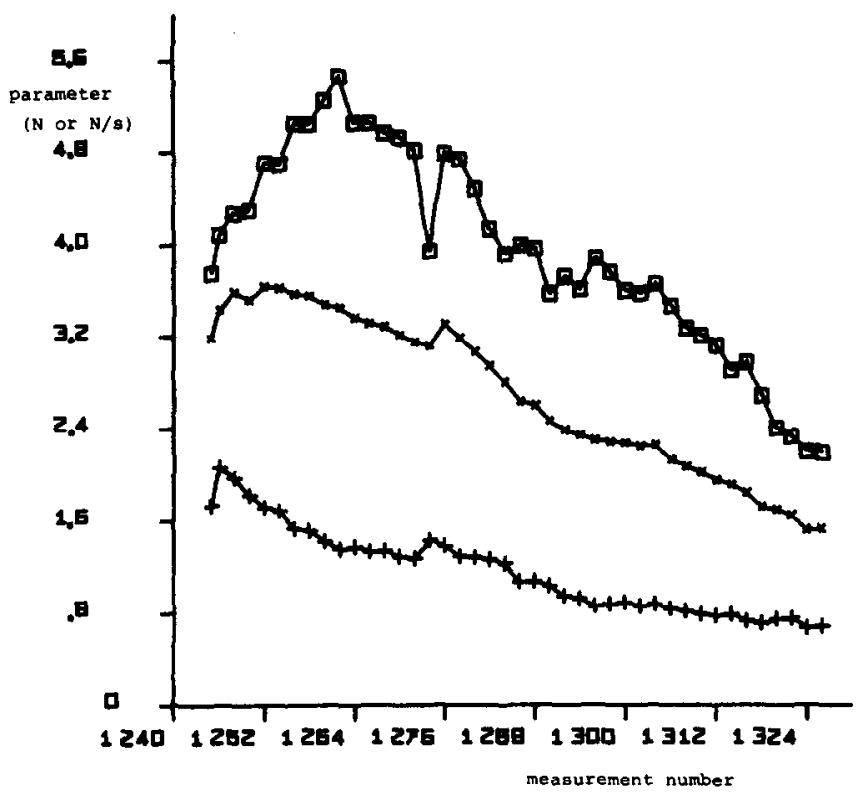

Figure 8 Parameters determined from 42 correction measurements on one strip as a function of measurement number. Correction measurements were taken at regular intervals of $10 \mathrm{~min}$ (with other measurements in between), except for measurements 1272 and 1274 which were separated by an interval of $40 \mathrm{~min}$. For all correction measurements a stimulation voltage of $20 \mathrm{~V}$, repetition frequency $100 \mathrm{~Hz}$, pulse duration 5 ms was used. $\square: F_{\text {iso }}(\mathrm{N}) ; \mathbf{x}: F_{\max }(\mathrm{N}) ;+: U(\mathrm{~N} / \mathrm{s})$.

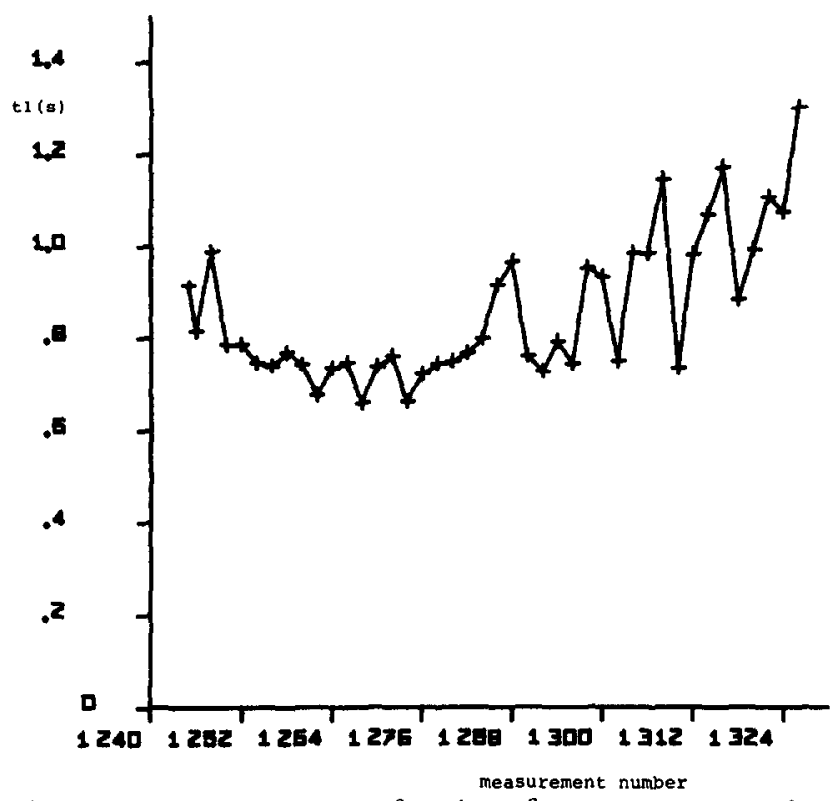

Figure 9 Parameter $t_{1}$ as a function of measurement number for the measurements displayed in Fig. 8.

parameters, averaged per strip, lay. Figures 8 and 9 show typical examples of their time-dependences. In general, the active force $F_{\max }$ and the parameters $F_{\text {iso }}$ and $U$ decreased with time. In half the cases the parameter $t_{1}$ increased significantly with time, showing that later in the experiment the muscle needed more time to become fully activated.

In 8 strips the parameter $U$ was found to correlate positively with stimulation voltage, stimulus pulse duration and stimulus frequency.

Figures 10,11 and 12 show typical results for four strips in which length was varied. As can be seen in

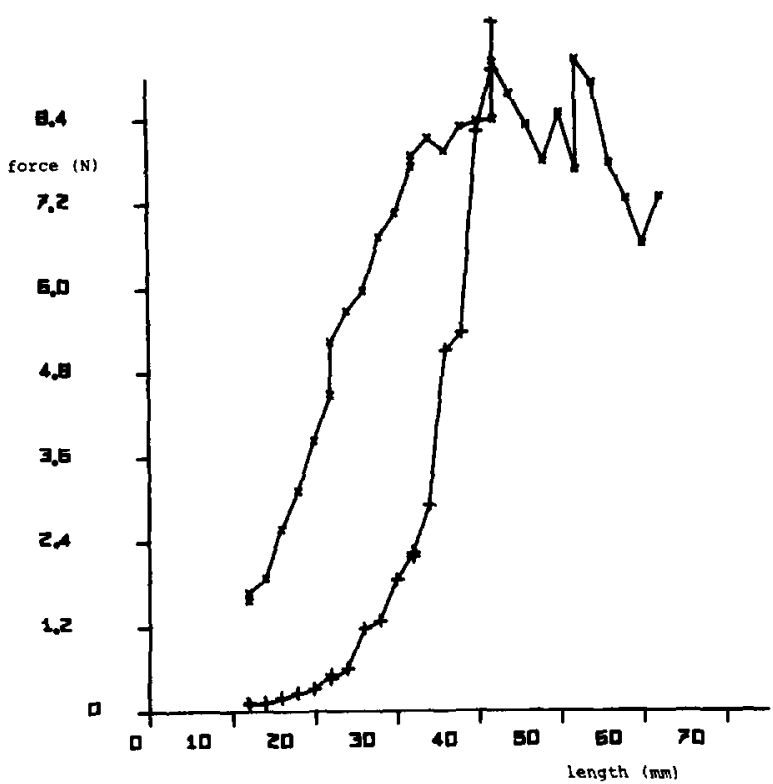

Figure 10 Measured active force $(x)$ and passive force $(t)$ as functions of length. Measurements were corrected for spontaneous decay due to the elapse of time. Strip was stimulated for $4 \mathrm{~s}$ every ten min (with correction measurements in between) with stimulation voltage $20 \mathrm{~V}$, repetition frequency $100 \mathrm{~Hz}$, pulse duration $5 \mathrm{~ms}$.

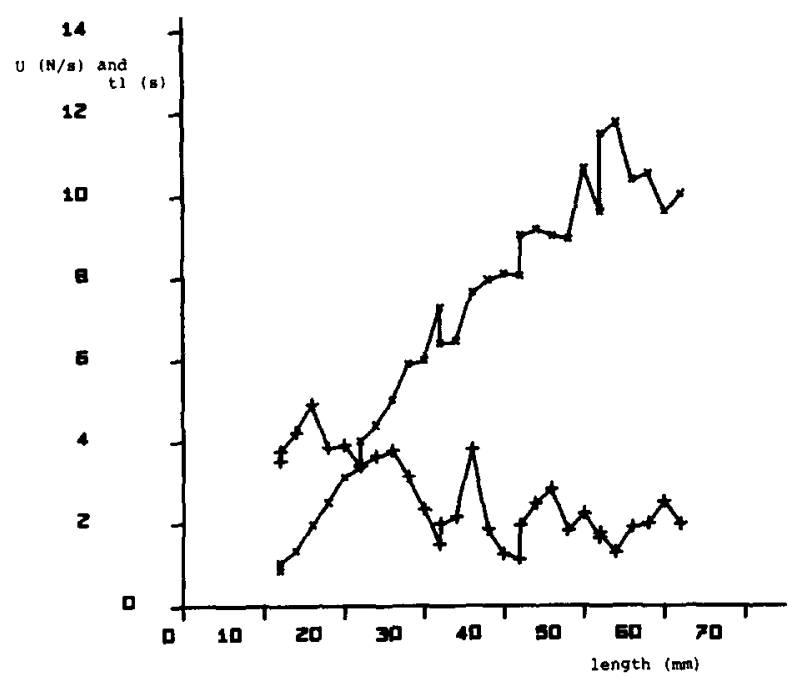

Figure 11 Parameters $U(\mathrm{x})$ and $t_{1}(+)$ as functions of length. Same measurements as Fig. 10.

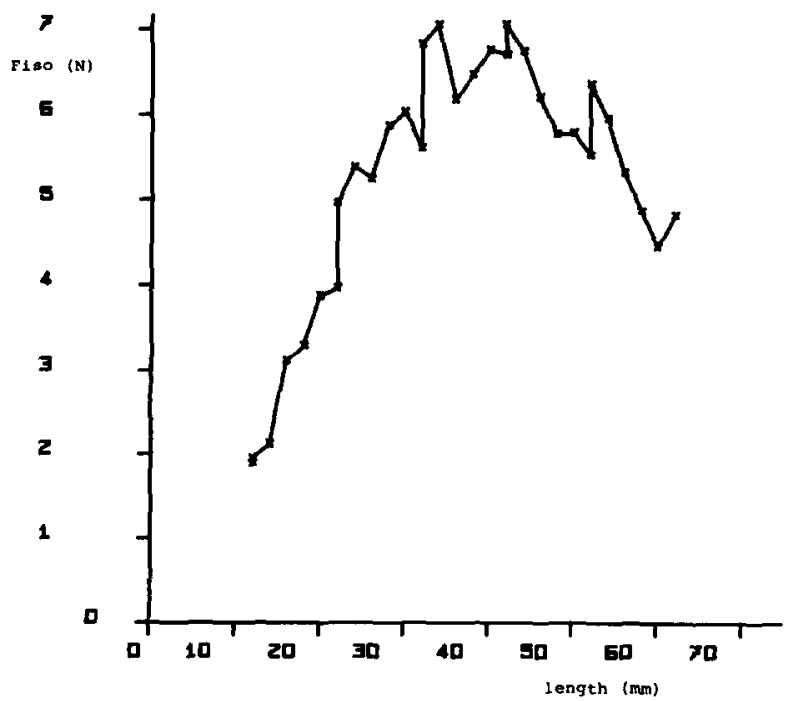

Figure 12 Parameter $F_{\text {iso }}$ as a function of length. Same measurements as Fig. 10 . 
Figure 10, both the active and passive forces initially increase with length, but the active force reaches a maximum. $F_{\text {iso }}$, see Figure 12, shows a similar maximum. $U$ and $t_{1}$, see Figure 11 , tend respectively to increase and decrease with increasing strip length.

In 4 strips the stimulation duration was varied between 2.5 and 16 seconds. In accordance with Figure 4 it was found that, although the maximal active force was usually positively correlated with stimulation duration, $F_{\text {iso }}$ and $U$ were not.

Finally, in three strips, pairs of contractions, separated by a variable time interval, were measured. Figure 13 shows, for four series of measurements, on one strip with different stimulus durations, that the second contraction was never significantly lower than the first one, but on the

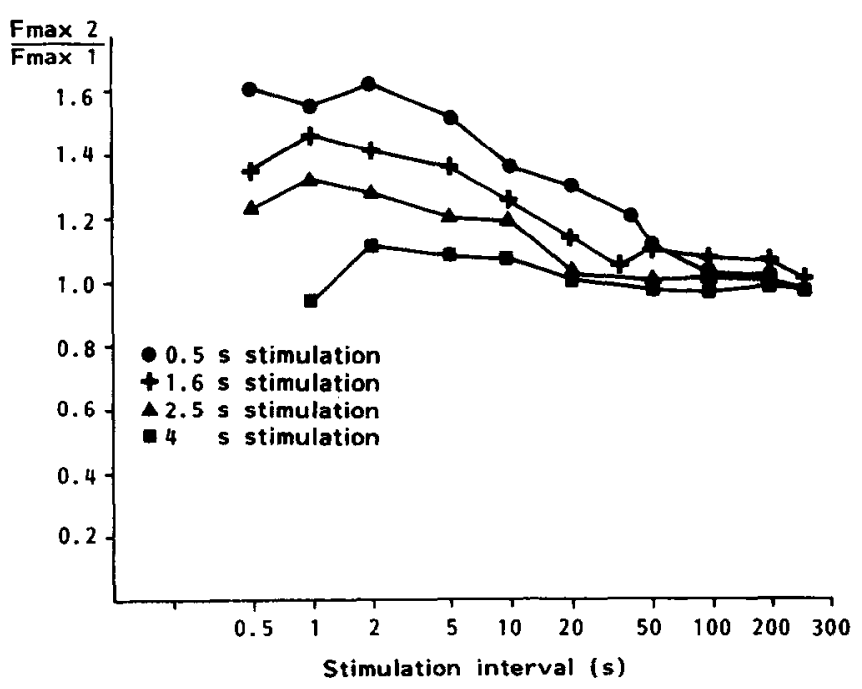

Figure 13 Quotient of maximum active forces in two successive contractions as a function of the time interval between the contractions. Four series of measurements on one strip, with different stimulation durations.

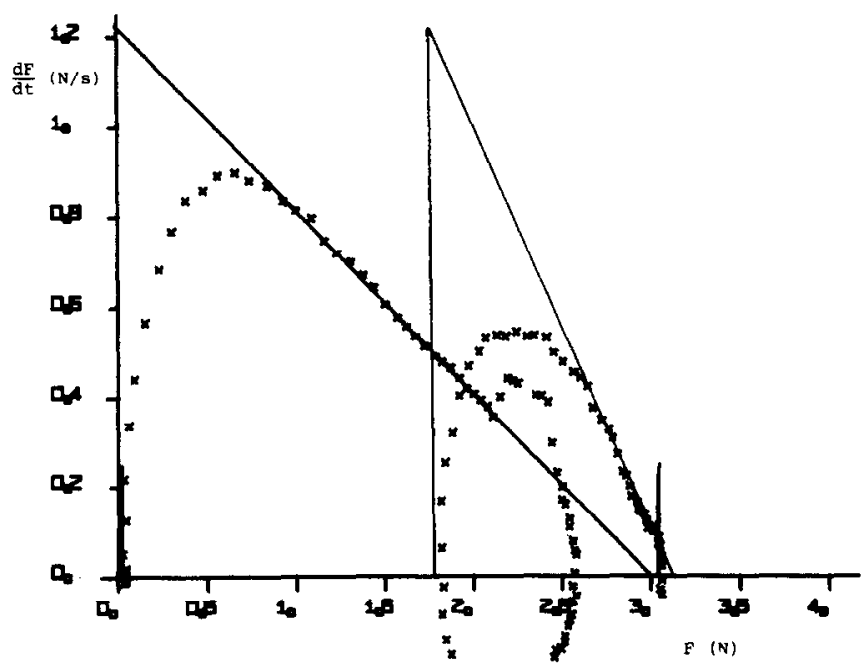

Figure 14 Phase plot of two successive isometric contractions separated by a short time interval. Muscle strip was stimulated for $4 \mathrm{~s}$, allowed to relax for $5 \mathrm{~s}$ and again stimulated for $4 \mathrm{~s}$. Stimulation parameters: $20 \mathrm{~V}, 100 \mathrm{~Hz}, 5 \mathrm{~ms}$. Straight line fitcing first contraction was fitted by computer, second straight line was inserted manually. contrary was usually facilitated by the first. Combined phase plots were made for the pairs of contractions separated by the smaller time intervals, as shown in Figure 14. It can be seen that $F_{\text {iso }}$ is almost identical for the 2 contractions, despite the obvious difference in $F_{\max }$. The values for the parameters $U$ and $t_{1}$ for the second contraction are difficult to judge, but clearly the straight line part of the phase plot, if it exists, is much steeper for the second contraction than for the first.

\section{DISCUSSION}

The force developed by smooth muscle strips in response to electrical stimulation depends on many variables. For pig bladder we have shown that, in our apparatus, using bidirectional field stimulation, optimal responses are obtained at $20 \mathrm{~V}, 100 \mathrm{~Hz}$, $5 \mathrm{~ms}$ stimulation. The average isometric stress developed was about $25000 \mathrm{~N} / \mathrm{m}^{2}$, which is comparable with the lowest values given for smooth muscle in the literature ${ }^{14}$, and is about twice the value found for the smooth muscle from rabbit urinary bladder ${ }^{24}$. Furthermore it is consistent with the physiological range of contraction pressures in the intact bladder ${ }^{4}$.

The three-parameter model which was used to describe the isometric contractions can be made plausible as follows. Suppose that during stimulation every muscle cell has a chance $p$ of passing from the non-contractile to the contractile state. (This chance might depend upon a spontaneous refractory cycle.) Then the rate of change of the total number of contracting cells would be:

$\frac{\mathrm{d} n}{\mathrm{~d} t}=p(N-n)$

where $N$ is the total number of cells available. Suppose that every contracting cell yields a given force $f$. Then the total force $F$ measured would be:

$F=n . f$

Combination of Equations (5) and (6) yields (1) with $F_{\text {iso }}=N . f$ and $c_{1}=-p$. The linear rise in activation (4) from 0 up to a maximum, at the beginning of the stimulation period, can then be accounted for by a similar increase in $N$. This might for example be due to the propagation of a contraction wave through the tissue at a constant speed. The existence of contraction waves in urinary bladder tissue has been postulated before, on other grounds ${ }^{25}$. Although since Hill ${ }^{13}$ numerous definitions have appeared for the activity, activation, or active state of muscle, most of them are related to 'the proportion of active sites active'21,26,27,28. Our description is compatible with this concept. By combination of (1) with the physical step function (4), then integration, the form of the isometric contraction in the time domain can be obtained: 


$$
\begin{aligned}
& F=F_{\text {iso }} \cdot \frac{t}{t_{1}}+\frac{F_{\text {iso }}}{c_{1} \cdot t_{1}} \cdot\left(1-e^{c_{1} \cdot t_{1}}\right) \quad \text { for } t<t_{1} \\
& F=F_{\text {iso }}+\frac{F_{\text {iso }}}{c_{1} \cdot t_{1}} \cdot\left[\left(e^{c_{1} \cdot t}\left(e^{-c_{1} \cdot t_{1}}-1\right)\right)\right] \text { for } t>t_{1}
\end{aligned}
$$

This is in effect a mono-exponential description of the rising part of an isometric contraction, modified to allow for a smooth initial rise in force, in contrast to models where tension is supposed to start rising sharply ${ }^{21}$. The smooth rise is always observed in practice and in the model is the result of using a physical step function in (4).

In conclusion, we propose a three-parameter model which describes quantitatively the development of force during electrical stimulation of smooth muscle strips under isometric conditions. In the model, isometric contractions are described by the three parameters, $U, F_{\text {iso }}$ and $t_{1}$. Of the three, the parameter $U$ is the most consistently related to the stimulus conditions. During the course of an experiment $U$ always decreased, even when the maximum active force did not decrease. It always increased with stimulation voltage, frequency and pulse duration. Since the parameter $U$ is also independent of the duration of the stimulus, in contrast to the maximum active force, it can be used to judge the effectiveness or intensity of muscle stimulation, even when the stimulation duration is not fixed. Clinically, the parameter $U$, as determined from isometric bladder contractions in patients, was shown to be correlated with the maximum contraction velocity of the bladder ${ }^{29}$. As the procedure for determining $U$ is relatively simple, it can be applied to the majority of clinical contractions, which are too noisy for more sophisticated analyses ${ }^{10}$. Therefore this parameter seems promising for clinical measurements of contractility. The second parameter, $F_{\text {iso }}$, is the isometric force which would have been developed after an infinitely long period of stimulation. The third parameter, $t_{1}$, is not correlated with the parameters $F_{\text {iso }}$ and $U$, which probably means that it is related to a different stage or process in the excitation-contraction coupling.

\section{REFERENCES}

1 Griffiths, D.J. Urodynamic assessment of bladder function. BR. J. Urol 1979, 49: 29-36.

2 van Duyl, W.A. Coolsaet, B.L.R.A. and van Mastrigt, R. A new clinical parameter for the assessment of contractility of the urinary bladder. Urol. Intern. 1978, 33: 31-39.

3 Griffiths, D.J., van Mastrigt, R., van Duyl, W.A., and Coolsaet, B.L.R.A. Active mechanical properties of the smooth muscle of the urinary bladder. Med. Biol. Eng. Comp. $1979,17-(3): 281-290$.

4 van Mastrigt, $R$. and Griffiths, D.J. The contractility of the urinary bladder. Urol. Intern. 1979, 34: 410-420.
5 van Mastrigt, $R$. The determination of contractile properties of the urinary bladder from isometric contractions. A pilot study. Urol Res. 1980, 8-(4): 237.

6 van Mastrigt, R. Female Incontinence. New York, Alan R. Liss Inc. $1981,67-71$.

7 van Mastrigt, R. Female Incontinence. New York, Alan R. Liss Inc. $1981,307-310$.

8 van Mastrigt, R., van Duyl, W.A. Principles of Bladder Function and Urodynamics. Utrecht, Lameris, 1981, 31-36.

9 van Mastrigt, R., Tauecchio, E.A. Series elastic properties of strips of smooth muscle from pig urinary bladder. Med. Biol. Eng. Comp. 1982, 20.(5): 585-594.

10 van Mastrigt, $R$. Determination of the contractility of children's bladders from isometric contractions, Urol. Int. 1983, 38: 354-362.

11 Byrne, J.C. and Tozeren, A. A contractility constant. Am. J Physiol 1983, 245: R673-R677.

12 Siroky, M.B. and Krane, R.]. A method for clinical assessment of detrusor muscle mechanics. Proc. 2nd Joint Meeting ICS-UDS, Aachen, 1983, 29-31.

13 Hill, A.V. The heat of shortening and the dynamic constants of muscle. Proc. Roy. Soc. B 1938, 126: 186-195.

14 Murphy, R.A. Contractile system function in mammalian smooth, nuscle. Blood Vessels 1976, 18: 1-23.

15 Plevnik, S., Suhel, P., Rakovec, S. and Kralj, B. Effects of functional electrical stimulation on the urethral closing muscles. Med. Biol. Eng. Comp. 1977, 15: 155-167.

16 Gillot, B., Vaysse, Ph., Josserand, P., Chisin, R and Juskiewenski, S. La stimulation electrique de detrusor: etude experimentale de l'excitabilite Vesicale. Ann. Urol. 1973, 7-(3) 157-161.

17 Bradley, W.E., Timm, G.W. and Chou, S.N. A decade of experience with electronic stimulation of the micturition reflex. Urol. Intern. 1971, 26: 283-302.

18 Edwards, L. and Malvern, J. Electronic control of incontinence. A critical review of the present situation. Brit. J. Urol 1972, 44: 467-472.

19 Coolsaet, B.L.R.A., van Duyl, W.A., van Mastrigt, R. and Schouten, J.W. Viscoelastic properties of bladder wall strips. Inv. Urol 1975, 12-(5) 351-356.

20 Aberg, A.K.G. and Axelsson, J. Some mechanical aspects of an intestinal smooth muscle. Act. Phys. Sc. 1965, 64, 15-27.

21 Gordon, A.R. and Siegman, M.J. Mechanical properties of smooth muscle. Am. J. Phys. 1971, 221, 1243-1254.

22 Meiss, R.A. Graded activation in rabbit mesotubarium smooth muscle. Am. J. Phys. 1975, 229-(2) 455-465.

23 Boom, H.B.K., Denier vd Gon, J.J., Nieuwenhuis, J.H.M. and Schiereck, P. Cardiac contractility: Actin-myosin interaction as measured from the left ventricular pressure curve. Eur. J. Card. 1973 1/2: 217-224.

24 Uvelius, B. Shortening velocity, active force and homogeneity of contraction during electrically evoked twitches in smooth muscle from rabbit urinary bladder. Acta Phys. Sc. 1979 106: 481-486.

25 van Duyl, W.A. Determination and interpretation of micro motion in urinary bladder smooth muscle: viscomotion model. Proc. 20th Int Conf. Riol Eng. London: 1980 364-367.

26 Wohlfart, B. and Noble, M.I.M. The cardiac excitationcontraction cycle. Pharnac. Ther. 1982 16: 1-43.

27 Pringle, J.W.S. Models of muscle. Symposia 1960 14: 41-68.

28 Chapman, A.E. and Harrower, P.T. Linear approximations of muscle mechanics in isometric contraction. Biol. Cyb. 1977 27: 1-7.

29 van Mastrigt, R. A clinical comparison of contractility parameters determined from isometric contractions and pressure-flow studies of the urinary bladder. J. UroL 1984 131-4/2: $190 \mathrm{~A}$.

30 Krebs, H.A. Untersuchungen über die Harnstoffbildung im Tierkorper. Hoppe Seyler's Z Physiol. Ch 1932, 210, 3367. 